This is an electronic reprint of the original article. This reprint may differ from the original in pagination and typographic detail.

Author(s): Kekäläinen, Tiia; Wilska, Terhi-Anna; Kokko, Katja

Title: Leisure Consumption and well-Being among Older Adults : Does Age or Life Situation Matter?

Year: $\quad 2017$

Version:

Please cite the original version:

Kekäläinen, T., Wilska, T.-A., \& Kokko, K. (2017). Leisure Consumption and well-Being among Older Adults : Does Age or Life Situation Matter?. Applied Research in Quality of Life, 12(3), 671-691. https://doi.org/10.1007/s11482-016-9483-6

All material supplied via JYX is protected by copyright and other intellectual property rights, and duplication or sale of all or part of any of the repository collections is not permitted, except that material may be duplicated by you for your research use or educational purposes in electronic or print form. You must obtain permission for any other use. Electronic or print copies may not be offered, whether for sale or otherwise to anyone who is not an authorised user. 
Kekäläinen, T., Wilska, T-A. \& Kokko, K.

Leisure consumption and well-being among older adults: Does age or life situation matter?

Authors:

Tiia Kekäläinen (corresponding author)

MSc. (Health Sciences), Postgraduate student

Gerontology Research Center and Department of Health Sciences, University of Jyväskylä, Finland Address: Viveca 146, Gerontology Research Center, PO Box 35, 40014 University of Jyväskylä, Finland.

tel. $+358408054245,+358408287501$

tiia.m.kekalainen@jyu.fi

Terhi-Anna Wilska

Ph.D. (Sociology), Professor of Sociology

Department of Social Sciences and Philosophy, University of Jyväskylä, Finland

Address: Y33 422, PO Box 35, 40014 University of Jyväskylä, Finland.

terhi-anna.wilska@jyu.fi

Katja Kokko

Ph.D. (Psychology), Research Director

Gerontology Research Center and Department of Health Sciences, University of Jyväskylä, Finland Address: Viveca 159, Gerontology Research Center, PO Box 35, 40014 University of Jyväskylä, Finland.

katja.r.kokko@jyu.fi

Compliance with ethical standards

Funding: The research was carried out with financial support from Tekes - the Finnish Funding Agency for Innovation. Project number: 2826/31/2014

Conflict of Interest: The authors declare no conflict of interest.

Human participants: The data for this study were collected by a mail survey. All participants received information about use of the data by covering letter and participated voluntarily in the study.

Acknowledgements: The authors wish to thank staff at the Unit of Economic Sociology at the University of Turku, Finland, for the data collection. 


\title{
Leisure Consumption and Well-Being among Older Adults: Does Age or Life Situation Matter?
}

\begin{abstract}
This study investigated the associations between leisure consumption and well-being in older adults (50-74 years old). To find out whether these associations are age-specific, they were compared with the associations observed among younger adults (18-49 years old). Differences between the older adults by age and life situation were also examined. This study was based on the "Finland 2014 - Consumption and Life style" survey $(\mathrm{N}=1351)$, conducted among a representative sample of the Finnish adult population. Well-being was measured as mental, economic and physical well-being. Objects of leisure consumption were grouped by factor analysis, and the associations between the resulting leisure consumption factors and the dimensions of well-being were studied using regression analysis. In addition, interaction terms were used to compare differences in the associations between younger and older adults, and among older adults varying in their life situation. In the older adults, appearance was related to better mental well-being, literature \& culture to better economic well-being, and exercise to better physical well-being. Travel was linked positively to all the dimensions of well-being, and health care negatively to mental and physical well-being. Some differences in the associations were observed between the younger and older adults; for example, exercise but not appearance was associated with better emotional well-being among the younger adults. In general, the associations were stronger in the older than younger adults. Among the older adults, age, employment status, and marital status moderated some associations. Further research, especially with longitudinal data, is needed to clarify the causal relationships between leisure consumption and well-being.
\end{abstract}

Keywords Leisure Consumption $\cdot$ Emotional well-being $\cdot$ Physical well-being $\cdot$ Economic wellbeing $\cdot$ Older adults 


\section{Introduction}

\section{Well-being}

Many studies have investigated the associations between leisure and well-being. A key problem with much of the literature has been inconsistent use of the concept of well-being, as there is no general agreement on what well-being is. Multiple terms, such as happiness, quality of life and life satisfaction have been used to refer to well-being. Diener (2006) defined well-being as an umbrella term that covers people's subjective valuations of their lives. Recently it has become generally accepted that well-being is a multidimensional construct (Dodge et al. 2012; Halleröd and Seldén 2013). Hence this study investigated perceptions of well-being according to three dimensions: mental well-being, economic well-being and physical well-being.

Mental well-being has mostly been studied in the field of psychology, where well-being is divided, for example, into emotional (i.e. subjective) well-being and psychological well-being (Ryan and Deci 2001). Emotional well-being includes the dimensions of happiness, positive affectivity, low negative affectivity and general satisfaction with life, whereas psychological well-being comprises dimensions related to the meaning of life and personal growth (Keyes 1998; Ryan and Deci 2001; Kokko et al. 2013). In this study, we focus only on the emotional dimension of mental well-being.

Economic and financial well-being are often used interchangeably (Joo 2008). In the social sciences, economic well-being is frequently equated with a "decent" standard of living, meaning the ability to lead a lifestyle that accords with the prevailing norms in society (e.g. Halleröd et al. 2006; Hamilton 2009; Aro and Wilska 2014). In previous research, economic well-being has been measured either by objective measurements, such as income and wealth, or by subjective questions. In this study, following the latter approach, we measure economic well-being by self-evaluated economic situation and socio-economic position.

A generally accepted definition of physical well-being is lacking, but in previous research it usually refers to both subjectively and objectively measured aspects of health. It has also been linked to the term health-related quality of life (Capio et al. 2014), and has been closely equated with physical health. The most widely used subjective measurement of physical well-being is self-rated or perceived health (Eriksson et al. 2001), which correlates strongly with objective health measurements (Wu et al. 2013), and is an independent predictor of mortality (Idler and Benyamini 1997). In this study, physical well-being was measured as self-rated health.

\section{Older adults as leisure consumers}

Previous research has indicated that leisure time relates to well-being. A recent review (Adams et al. 2011) and meta-analysis (Kuykendall et al. 2015) showed that active leisure is associated with higher well-being. Leisure activities have usually been measured by frequency or the amount of time spent 
on them. Money spent on leisure activities has been less used as a measurement instrument, despite the fact that nowadays leisure and consumption are hard to separate. It has been argued that the lives of postmodern citizens increasingly revolve around leisure and entertainment (e.g. Bryman 2004; Ritzer 2010). Spending on leisure activities and leisure products are also seen as reflecting a person's values, attitudes and lifestyle (Miles 1998; Taylor 2002; Katz-Gerro 2004; Sassatelli 2007; Smith Maguire 2008; Wheaton 2010).

Participation in leisure activities requires that an individual has free time after going to work and doing housework. Activities involving consumption also require that the individual has the necessary financial resources. Leisure time has increased during the past twenty years in Finland (Official Statistics of Finland 2011), the context of the present study, while the same rising trend is also apparent, for instance, in the United States and Canada (OECD 2009). As expected, retired people have more leisure time than individuals of working age. Furthermore, in all the OECD countries, 45- to 64 year-olds have more leisure time than younger adults (aged 25-44) (OECD 2009). The same group also has the highest expenditure on consumption, both overall and on leisure (Official Statistics of Finland 2012).

No general definition or age range exists for older adults. According to Yoon et al. (2009), in consumer research even 50-year-olds may be called senior consumers. Yoon et al. (2009) also point out that older adults can be divided into different subgroups: youngest olds (50-59 years), younger olds (60-74), older olds (75-84) and oldest olds (85+). Of these subgroups, the first two have more money to spend on leisure than younger adults, and better health than the oldest ones, and hence more opportunities for active leisure (Yoon et al. 2009). The amount of consumption tends to decrease with age, and people over 75, in particular, spend less on leisure and entertainment than younger age groups (Official Statistics of Finland 2012; Foster 2015). In light of these findings, this study focuses on the associations between leisure consumption and well-being among older adults, in this instance, 50- to 74-year-olds.

\section{Leisure consumption and well-being}

Adequate material situation, usually measured by income and/or wealth, is a prerequisite for leisure consumption, and also for well-being. Veenhoven and Ehrhardt (1995) propose the livability theory (also known as need theory), according to which better living conditions are associated with greater happiness. However, this association holds only until basic human needs are fulfilled. Thereafter, expenditure on luxuries no longer increases happiness (Veenhoven and Ehrhardt 1995). This is also in line with the findings of Easterlin (2002), who suggests that person's happiness increases with income, but only up to a certain point. The role of material situation in well-being also depends on how well-being is measured (Christoph 2010): according to Headey et al. (2008), income, wealth and consumption are associated with better life satisfaction, particularly with the material standard of living (based on subjective evaluations of income and financial situation). 
Leisure consumption can be considered extra consumption, which is possible after the basic needs are fulfilled. According to DeLeire and Kalil (2010), after controlling for material situation and other demographic factors, spending on leisure activities was associated with happiness, unlike spending on everyday necessities or durable goods. They also found that the association between leisure consumption and subjective well-being was, at least partly, mediated by social connectedness. Hence it was not leisure consumption as such but social connections during leisure that was linked to better well-being. Therefore the links between leisure consumption and well-being may result more from leisure content than the amount of consumption. While consumption has been seen as a part of economic well-being, along with income and wealth (Headey et al. 2008), leisure consumption may rather indicate preferences in one's investment in leisure and different leisure activities than solely economic well-being. In this study, we take consumption as a proxy for leisure activities. However, research on leisure, consumption and well-being is not free of problems. One problematic issue is the narrow definition of well-being, often measured solely as emotional well-being, using indicators such as happiness, used in much of the previous consumption and well-being research. Another is the lack of studies comparing different kinds of leisure consumption in relation to well-being. Moreover, the associations between leisure and well-being may also differ at different stages of life. Our purpose was to contribute to filling these gaps in the literature.

Leisure activities may have specific associations with different dimensions of well-being. This has been pointed out by Lee et al. (2014), who investigated the associations between various leisure activities and dimensions of quality of life. Time spent on media use (such as watching TV, reading newspapers, accessing the internet) as well as on sport and outdoor activities was associated with psychological and overall quality of life. Media use was also associated with social relationships, whereas sport and outdoor activities were related to the physical quality of life. To the best of our knowledge, apart from that study, hardly any research exists in which different dimensions of wellbeing (or concepts bearing any similarity to well-being) have been compared.

In relation to leisure and consumption, the mental dimension of well-being has been the most studied, mainly using such indicators of emotional well-being, as happiness, life satisfaction and affectivity. For example, spending on leisure travel and sports has been associated with happiness (DeLeire and Kalil 2010) and participating in culture with life satisfaction (Leadbetter and O'Connor 2013). Consumption of luxury products has also been associated with better life satisfaction and positive affectivity, but this association is stronger among people with materialistic values (Hudders and Pandelaere 2012). However, in general, happiness has been related to altruistic use of money, spending on experiences rather than on material products and spending on small pleasures often rather than on big purchases rarely (Van Boven and Gilovich 2003; Dunn et al. 2011). Of the well-being dimensions, physical well-being has been less studied with respect to leisure activity and consumption, and in the studies reported it has mostly been measured by self-rated health. Participation in leisure physical activity in particular (Penedo and Dahn 2005; Galan et al. 2010; 
Leadbetter and O'Connor 2013), but also participation in culture (Leadbetter and O'Connor 2013) have been associated with better self-rated health. Economic well-being, in turn, has hardly been studied in relation to leisure. However, it is reasonable to assume that the association between leisure consumption and economic well-being is bidirectional. That is, on the one hand, economic well-being can be considered a prerequisite for high expenditure on leisure, while, on the other hand, leisurerelated consumption may promote feelings of economic well-being.

\section{Moderators of leisure activities and well-being}

Associations between leisure consumption and well-being may differ among age groups. These differences may be a result of different goals and values held by at different ages. According to the socioemotional selectivity theory (Carstensen et al. 1999), older adults concentrate more on social goals related to emotion regulation, and spend time with their families to obtain positive feelings. Younger adults favor social goals related to knowledge acquisition and try to achieve these by developing new social relationships (Carstensen et al. 1999). Windsor and Anstey (2010) have also reported that social interaction with friends has a stronger association with emotional well-being among younger adults, whereas among middle aged adults greater emotional well-being is derived from social interaction with their family. Personal goals and their achievement are important to wellbeing (e.g. Sheldon and Elliot 1999; Hietalahti et al. 2016), and leisure activities and consumption may offer a means to this end (Adams et al. 2011; Moschis 2012). Brajša-Žganec et al. (2011) showed that the associations between leisure activities and emotional well-being (measured by life satisfaction and happiness) were somewhat different between different age groups. Socializing and going out was associated with emotional well-being in persons aged 31-60, but not among the older participants. Additionally, visiting cultural events was linked to emotional well-being among participants aged over 30, but not among 18- to 30-year-olds. These findings support the socioemotional selectivity theory. With the exception of this study by Brajša-Žganec et al., research on age differences in relation to leisure and well-being is nonexistent.

In addition to personal goals, older and younger adults may also have different values. According to Schwartz's theory of basic values (Schwartz 2006, 2012) and the empirical evidence in support of it (e.g. Gouveia et al. 2015), basic personal values differ by age. In general, conservational values (e.g. tradition) are more important to older adults whereas values related to openness to change (e.g. hedonism) are more important to younger adults. These changes in personal values with age may originate from different life stages or physical aging, and are in line with the changes observed in personal goals (Schwartz 2006, 2012; Gouveia et al. 2015). Personal values may also guide consumer behavior (Schwartz 2006). Hudders and Pandelaere (2012) showed that the positive association between luxury consumption and emotional well-being is stronger among individuals with materialistic values. It has further been shown that younger adults have more materialistic values than older adults (Valkeneers and Vanhoomissen 2012). Hence these results support the idea that, owing to 
different personal values, different types of leisure consumption may be related to well-being in younger and older adults. For this reason and to better understand age-specific associations, it is important to compare older and younger adults.

There may also be differences within older adults, and thus they should not be seen as a homogenous group (Yoon et al. 2009). First of all, the age difference between a 50-year-old and a 74year-old individual is almost twenty-five years. To take this into account, we investigated possible age differences between older adults by dividing them into two subgroups: ages 50-61 and ages 62-74. Henceforth, we refer to the 50- to 61- year-olds as older middle-aged and the 62- to 74-year-olds as young olds. Second, the life situations of older adults may also moderate the associations between leisure consumption and well-being. For example, individuals in working life and those in retirement have different leisure-time possibilities. It has been shown that satisfaction with and engagement in leisure are more strongly associated with emotional well-being among retired people than people still in working life (Kuykendall et al. 2015). Marital status has been found to moderate the associations between leisure time physical activity and depression (Wang et al. 2011), and different leisure activities were associated with quality of life among urban and rural older adults (Sewo Sampaio et al. 2013). According to these observations, work situation, marital status and residential area are considered possible moderators in the present study. Since gender, education, and income have been associated with both consumption patterns (e.g. Headey et al. 2008; LeRoux et al. 2008; Segal and Podoshen 2013) and well-being (Diener et al. 1999, Dolan et al. 2008), they were controlled for in this study.

\section{Aim of the study and study questions}

The aim of this study was to investigate the associations between various types of leisure consumption and different dimensions of well-being in older adults, i.e. persons aged 50-74. In order to analyze whether the obtained associations are age-specific, they were compared with the associations observed for younger adults (18-49). We also investigated whether age or life situation moderated these associations among older adults. We used a representative sample of the Finnish population aged 18-74 $(\mathrm{n}=1351)$. The main research questions were:

1. What kinds of leisure consumption are associated with mental, economic and physical well-being among older adults and do these associations differ from those among younger adults?

2. Are there differences in these associations among older adults with respect to age or life situation?

On the basis of the previous research, we hypothesized, first that different kinds of leisure consumption are associated with different domains of well-being. For example, we expected spending on culture to be associated with mental well-being, and spending on exercise with physical wellbeing. Second, we hypothesized that some associations are specific to older adults. For example, culture may be more important to well-being of older adults, while for younger adults appearance may be more important. Third, we assumed that age and life situation may modify these associations 
among older adults. The associations between leisure consumption and well-being may be stronger among retired older adults than among older adults still in working life. The associations may also be stronger among unpartnered than partnered older adults. There may also be differences between types of residential area; for example technology and culture may be linked to well-being among older adults in urban areas, but not among those in rural areas.

\section{Data and methods}

\section{Data}

The data for this study were drawn from the "Finland 2014 - Consumption and Way of Life" survey. The survey investigated attitudes and values towards consumption and consumption practices as well as lifestyle indicators among the Finnish population (Koivula et al. 2015). This study used the data collected in 2014, when the target sample was 3000 Finnish speaking participants aged 18-74. The sample was selected from the Central Register of Population database by random sampling (Koivula et al. 2015). The survey was sent to 2971 participants. The responses could be sent by regular mail or via the internet. For those who did not answer, even after the first reminder, the survey was sent again one month later, and a second reminder two weeks thereafter. After all, $46 \%(\mathrm{~N}=1351)$ of sample answered the survey, and 760 of the participants were aged 50 or older.

Compared to the Finnish population, the sample was representative, but slightly skewed for gender and age. Women answered more frequently than men, and participants aged 65-74 were overrepresented and participants aged 18-45 under-represented. Therefore, the data contained weight variable calculated for gender and age, which corrected the skewness (Koivula et al. 2015). When the weight variable was used, the analyses were conducted with an older adult sample size smaller $(\mathrm{N}=589)$ than the original sample size $(\mathrm{N}=760)$, as older adults were over represented in the final sample.

\section{Measures}

Leisure consumption. Participants were asked to state, on a response scale from 1 (much more) to 5 (much less), how much they spend on different goods and services compared to the "average" consumer. To simplify interpretation of the analyses, the responses were reverse-scored, a bigger value representing a higher level of consumption. 15 variables on the amounts of time and money spent on leisure were included in the factor analysis.

Well-being. Emotional well-being (EmWB) was constructed using two questions: "How happy are you in general?" and "How satisfied are you with your life at present?" Answers were given on a scale from 1 (very happy/satisfied) to 5 (very unhappy/dissatisfied). The responses were reversescored and their mean value formed the EmWB variable (Cronbach's alpha 0.86). Economic well- 
being (EcWB) was measured by items on financial situation and occupational/social status using the same reverse-scored scale. The mean value formed the EcWB variable (Cronbach's alpha 0.71). Physical well-being was measured by self-rated health (SRH) with the question "How would you describe your health in general?" on a response scale from 1 (very good) to 5 (very bad). Because only $1.7 \%(\mathrm{n}=23)$ of the participants estimated their health as very bad, values 4 and 5 were combined and then reverse-scored in the same way as the other variables.

Age. Participants were divided into two age groups: 18-49 (0) and 50-74 (1). This binary variable was used when comparing the older adults with the younger ones. All the other analyses were conducted only for the older age group (1). The older adults were also subdivided into two age groups: 50-61 (0) and 62-74 (1). This variable was used in answering research question 2.

Life situation. Life situation was measured by employment status, marital status, and residential area. Employment status was asked with the alternatives employed/laid off, unemployed/job applicant, study, retired, and other. Because the interest was in investigating differences between employed and retired older adults, we formed a binary variable: employed (0) and retired (1). Of the older adults, $45 \%$ were employed, $48 \%$ were retired, and only $7 \%$ were not either employed or retired. Marital status was asked with the alternatives single, cohabitation, married/registered partnership, divorced or widow. For the analyses, these alternatives were collapsed into a binary variable, living without a partner (0) including single, divorced and widowed, or living with a partner (1) including cohabiting and married/registered partnership. $73 \%$ of the older adults were living with a partner. The residential area variable was binary: the options were urban area (0) and rural area (1). $76 \%$ of the older adults were urban residents.

Control variables. Analyses were controlled for income, educational background, gender and age. For income we calculated the variable household's income per consumption unit. When calculating income per consumption unit, we used the OECD'-s adjusted consumption unit scale recommended by Eurostat, which takes differences in household size into account. The consumption unit $(\mathrm{K})$ was calculated using the traditional OECD scale: $\mathrm{K}=1+(0.7 *(\mathrm{a}-1)+0.5 * \mathrm{~b})$, where $\mathrm{a}=$ adults in household (aged 18 and over) and $\mathrm{b}=$ children in household (aged under 18). Educational background was measured as education after comprehensive school on a 7-category scale. Gender was a binary variable with male (0) and female (1). Age as a continuous variable was used as a control variable in the regression analysis for the separate age groups.

\section{Data analyses}

The data analyses were performed using IBM SPSS Statistics 22.0 (IBM Corp. 2013). Little's MCAR test was applied first and it showed that missing values were missing completely at random. This allowed us to exclude missing values pairwise. A significance level of $95 \%$ was used in all statistical analyses. Weight (adjusted by gender and age) was used in all analyses with the exception of the regression analyses, where gender and age, among other variables, were used as control variables. 
First, factor analysis was used to compress the dimensions of leisure consumption. The extraction method of Principal axis factoring and the rotation method of Oblimin with Kaiser Normalization were used. Variables were included in a factor only if their factor loading was above 0.4 (recommendation of Stevens 2009). The factor analysis identified four factors (with Eigenvalues > 1), as presented in Table 1, along with Cronbach's alpha levels that were satisfactory given the small number of variables per factor. These four factors combined explain $44 \%$ of the variance. On the basis of the variable loadings on each factor, average sum scores for the four leisure consumption factors were calculated and used in the further analyses. Travel, exercise and health care did not load sufficiently on any factor, and hence were used separately in the analyses.

(Table 1)

Multiple regression analyses were conducted to examine what kinds of leisure consumption best explained the well-being variables. EmWB and EcWB were analyzed with linear regression using the enter method. The control variables were age, gender, education and income. Although the leisure consumption variables exercise, travel and health care, and the control variable education, were ordinal, they were used as a continuous variables in all analyses after their linear association with the dependent variables was confirmed. This is commonly done if there are at least 5 categories (HaggerJohnson 2014, pp. 246). Because SRH was an ordinal variable with four categories, it was analyzed with cumulative odds ordinal logistic regression with proportional odds. The link function used in all the ordinal regressions was logit. Otherwise ordinal regression was performed in the same way as linear, and thus all the consumption variables and control variables were added to the model simultaneously.

Possible interactions between leisure consumption variables and age, marital status, employment status and residential area were also investigated. These interactions were tested as we hypothesized that these variables might moderate the associations between leisure consumption and well-being. All the possible moderators were binary variables coded 0 and 1 . Because the leisure consumption variables were continuous, they were standardized before calculating the interaction terms, as is generally recommended (Dawson 2014). The interaction terms were first tested in the regression analyses, which included only the main variables (leisure consumption variable and moderator variable) and interaction term. Thereafter, only statistically significant interaction terms were taken for the regression analyses with all the consumption and control variables (final models). Since the purpose was to investigate the existence of different kinds of interactions, and not to compare them, all the significant interaction terms were tested separately in the final models. This procedure was the same in both the linear and ordinal regressions for all the well-being variables. The interaction terms, which remained significant in the final models, are shown in the figures to clarify the interpretation. For the figures, the consumption variables, rated on a scale of 1 to 5 , were collapsed into three categories: low $<2,5 ; 2,5 \leq$ medium $\leq 3,5$; and high $>3,5$. 


\section{Results}

\section{Descriptive statistics}

Older adults' descriptive statistics are presented in Table 2 with comparison data on younger adults. In the well-being measurements, the older adults, compared to the younger adults $(p<.001)$ gave weaker self-ratings only for health. Otherwise, no statistically significant differences in EmWB or EcWB were observed between the two age groups. Of the leisure consumption objects, the older adults spent the most on health care, travel and exercise, and the least on appearance and indulgence. In comparison with the younger adults, they spent more on health care, and less on technology, indulgence and appearance.

(Table 2)

The associations between leisure consumption and well-being were first examined using Spearman's correlation. The correlation matrix (presented in Table 3) shows that among the older adults almost every type of consumption correlated significantly with all the well-being variables. The perception of higher than average consumption was associated with better well-being. An exception was health care, which correlated negatively with SRH. Fisher's r-to-z transformation (z-test) was used to investigate whether the correlations for the older adults differed from those for the younger adults. The main difference was that the associations between consumption and well-being were stronger among the older than younger adults.

(Table 3)

\section{Associations between leisure consumption and well-being dimensions among older adults}

In order to find out how spending on leisure predicted the three measurements of well-being in older adults, multiple regressions were performed. The results are presented in Table 4 along with the results for younger adults. After adjusting for age, gender, education, and income, higher levels of expenditure on travel and appearance, and lower levels of expenditure on health care, were related to higher levels of EmWB. Higher expenditure on literature \& culture and travel were associated with better EcWB. Higher expenditure on exercise and travel, and lower expenditure on health care, were linked to better SRH.

(Table 4)

\section{How do older adults differ from younger adults?}

Regression analyses were conducted for both the older and younger age groups (Table 4). The younger group was included to ascertain whether the associations were specific to older adults. The 
results showed a number of differences between the younger and older age groups in the leisure consumption and well-being measurements. Spending on appearance was associated with EmWB only among the older adults. Spending on technology and indulgence were linked to EcWB in the younger, but not older adults, and high expenditure on appearance was related to SRH in the younger adults, as compared to travel in the older adults. The models seemed to explain less of the variance of well-being among the younger than older adults. The final models explained $4 \%$ vs. $10 \%$ of EmWB, $26 \%$ vs. $31 \%$ of EcWB, and $17 \%$ vs. $23 \%$ of SRH in the younger and older adults, respectively.

We also investigated whether the interaction terms calculated between the age and leisure consumption variables were significantly related to different indicators of well-being. The interaction terms between age and indulgence, and age and appearance, were related to EmWB, and that between age and literature \& culture was related to EcWB (Table 4). In the models with all the leisure consumption variables and control variables, the interaction terms between age and indulgence and age and appearance remained significant for EmWB, whereas the interaction term between age and literature \& culture in relation to EcWB did not. As shown in figures 1 and 2, high expenditure on indulgence and appearance were related to higher EmWB in older adults than younger adults.

Fig. 1 Interaction effect between expenditure on indulgence and age on emotional well-being $(n=1307)$

Fig. 2 Interaction effect between expenditure on appearance and age on emotional well-being $(n=1307)$

\section{Differences within older adults}

We investigated whether age or life situation would modify the associations between leisure consumption and well-being (Table 5). We started with age: the group of older adults was subdivided into two classes: older middle-aged (50-61 years) and young olds (62-74 years). Four significant interaction effects were found: age in interaction with literature \& culture was related to EmWB, age in interaction with indulgence was associated with both EmWB and SRH, and age in interaction with travel was linked to SRH. Of these, two also remained significant in the final models: the interaction terms between age and literature \& culture for EmWB and between age and travel for SRH. These two interaction effects, which were stronger in the older middle-aged than young olds, are presented in figures 3 and 4.

The moderator role of life situation was tested using employment status, marital status and area of residence as moderators. The interaction term calculated between employment status and health care was significantly associated with EmWB. In the final model, containing all the leisure consumption variables and control variables, it was no longer significant. The interaction terms between employment status and both indulgence and exercise were significantly related to EcWB. 
However, in the final models only the interaction term between employment status and exercise remained significant (Fig. 5). The interaction term between marital status and exercise was related to SRH. This interaction term also remained statistically significant in the final models, and is shown in figure 6. As can be seen in figures 5 and 6, low expenditure on exercise was associated with lower EcWB among the retired older adults than working older adults, while older adults living without a partner reported worse SRH than older adults living with a partner. When expenditure on exercise was high, there were no differences between the groups.

(Table 5)

Fig. 3 Interaction effect between expenditure on literature \& culture and age on emotional well-being $(\mathrm{n}=575)$

Fig. 4 Interaction effect between expenditure on travel and age on self-rated health $(n=571)$

Fig. 5 Interaction effect between expenditure on exercise and employment status on economic wellbeing $(\mathrm{n}=531)$

Fig. 6 Interaction effect between expenditure on exercise and marital status on self-rated health $(\mathrm{n}=571)$

\section{Discussion}

This study investigated the associations between different kinds of leisure consumption and different dimensions of well-being in older adults (50- to 74-year-olds). In general, the results revealed some significant associations, for the most part in line with our expectations. Spending on travel was associated positively with all the dimensions of well-being. This supports previous research findings, where spending on travel (DeLeire and Kalil 2010) and experiences (Van Boven and Gilovich 2003) have been associated with better well-being. The association between exercise and physical wellbeing is also in line with previous findings (e.g. Penedo and Dahn 2005; Galan et al. 2010). At the same time it was somewhat surprising that, in contrast to previous research (e.g. Penedo and Dahn 2005), exercise was not linked to mental well-being. Higher expenditure on health care was associated with lower mental and physical well-being. This is understandable, if health care is mainly understood as medical treatment. Economic well-being, in turn, was linked to spending on travel and on literature $\&$ culture. While on the one hand, cultural consumption and travelling may enhance a sense of economic well-being, on the other hand these may be important objects of consumption only if economic resources are good. In summary, the results of this study support the idea that different kinds of leisure consumption are associated with different dimensions of well-being. It is important to note that, according to the present findings, not all kinds of leisure consumption are related to wellbeing. For example, spending on technology or indulgence was not associated with any dimension of 
well-being among the older adults. This supports Brown et al. (2015), who found that only active, not passive, leisure activities were linked to better well-being. Elliot et al. (2014) also reported that use of technology was not associated with well-being among older adults. These results are also reasonable in light of the livability theory (Veenhoven and Ehrhardt 1995) and former findings on consumption and subjective well-being (Headey et al. 2008, DeLeire and Kalil 2010), according to which it is not leisure consumption itself that contributes to well-being, but the content and quality of leisure.

To find out whether these associations were age-specific, we compared them with the associations observed for younger adults. The results indicate that the most notable difference between the two age groups is that the associations between leisure consumption and well-being were stronger in the older adults. The results also suggest that some associations are age-specific to older adults. Particularly surprising is that spending on appearance was linked to better mental well-being only among the older adults, despite the common assumption that younger adults are more interested in fashion and have more materialistic values than older ones (e.g. Valkeneers and Vanhoomissen 2012). The results are in line with the assumptions of the socioemotional selectivity theory (Carstensen et al. 1999) in that for older adults positive feelings were important for well-being while for younger adults the acquisition of new knowledge was associated with well-being. Older adults, however, may also seek pleasure by spending on clothes, interior decoration or beauty care. It has been proposed that different objects of consumption are related to well-being at different life stages (DeLeire and Kalil 2010); this study partially supports this idea. However, some associations, such as those between exercise and physical well-being, and travel and emotional well-being, seem to be common to all age groups.

The second interest of this study was to find out whether differences in relation to leisure consumption and well-being exist among older adults. The associations between cultural consumption and mental well-being, and between travel and physical well-being were stronger among the older middle-agers than young olds. It is possible that if older middle-agers still have children at home and are engaged in working life, then spending time with literature and culture or travelling may, by giving them a chance to relax, enhance their well-being. However, the only difference between retired and employed older adults was that low expenditure on exercise was associated with low economic well-being among the retired older adults. Consequently, the differences between the two age groups are not a result of employment status. Furthermore, the results of this study do not strongly support the notion that associations between leisure and well-being are stronger among retired people (Kuykendall 2015). Of the other issues related to life situation, the only significant difference between the groups was that expenditure on exercise was more strongly associated with physical well-being among unpartnered than partnered older adults. This is in line with findings of Wang et al. (2011), which suggest that exercise has a preventive impact on depression, especially among divorced, separated and widowed women. In general, single middle-aged and older adults have poorer health 
than their married counterparts (Robards et al. 2012); hence the health-promoting impact of exercise may be more important to them. Area of residence did not show any moderator effects.

The present results have to be interpreted cautiously, first, because they were based on crosssectional data. Consequently, it is not possible to draw any conclusion about the causal relationships between leisure consumption and well-being, that is, whether leisure consumption improves wellbeing, or whether well-being enhances leisure consumption. For example, lower expenditure on health care hardly improves well-being, but it is more likely a consequence than an cause of weak wellbeing. Further, the associations may be bidirectional, so that consumption and well-being form mutual cycles. Second, it may be speculated whether consumption is a valid measurement of leisure, or whether it only informs about the economic resources available for leisure consumption. We shall return to this point when considering the strengths of the study.

Third, it is important to consider the meaning of the different consumption factors. For instance, the factors under "indulgence" comprised spending on self-pampering, having fun/socializing and alcohol. For some people, this type of consumption means spending time with friends and taking time out for oneself, which may contribute to well-being. For others it means heavy drinking and behaving irresponsibly, which may be detrimental to well-being. Similarly, spending on health care may mean different things to different people. For some, it may be restricted to the obligatory costs of medical care, whereas for others it may mean investing in a healthy lifestyle. Hence spending on specific items may have different meanings for different persons.

Fourth, the groups for this study were formed with rather broad age ranges. This is evident in the comparison between younger and older adults, where the age range of the younger adults (18-49 years) was particularly wide. However, because the main interest was in older adults, and younger adults were only used as a comparison group, we did not see any necessity to divide them into smaller groups. A similar age grouping has been used previously; for example, Toepoel (2013) compared older adults (aged 55+) with younger adults (18-54 years). In this study, age was also controlled for as a continuous variable in the analyses.

Notwithstanding the limitations of the present study, it has several strengths. First, it was based on a relatively large, randomized sample size of individuals representing the Finnish adult population. Therefore the results can be generalized to the Finnish adult population aged 18-74. Second, different kinds of leisure consumption have not previously been compared in relation to well-being, and particularly in relation to different dimensions of well-being. Hence, the findings of the present study broaden the existing knowledge on leisure consumption and well-being. Third, although economic resources clearly have some impact on leisure consumption, the present results are largely consistent with previous results on leisure and well-being. This validates the usefulness of consumption as a measure of leisure activities. We also controlled the analyses for income per consumption unit, and hence the associations between leisure consumption and well-being are not solely a consequence of economic resources. 
In conclusion, our results showed that leisure consumption and well-being are linked, and the associations vary by the dimensions of well-being, age and life situation. Leisure consumption may function as an indicator of an individual's leisure preferences. In general, the associations of leisure consumption with well-being were stronger among the older than the younger adults, implying that when people have fewer time constraints they invest in leisure activities that maintain their wellbeing. The results showed that among the older adults whose expenditure on exercise was low, economic well-being was lower among the retired than among the employed. It is possible that, among employed older adults, time is the most important constraint on exercise, while among retired older adults it is financial. Hence, free and low-priced leisure time activities should also be available to older adults so as to reduce the importance of material resources for the well-being of this population segment. Furthermore, older adults should not be regarded as a homogenous age group, and thus leisure activities should be considered more broadly and in a more individual way. In the future, it would be important to replicate our findings by applying a multidisciplinary perspective in order to link leisure consumption and well-being with each other. It would further be important to consider well-being as a multidimensional construct. Finally, future research would benefit from longitudinal research designs which would make it possible to obtain information about the causal relations between leisure and well-being.

\section{References}

Adams, K. B., Leibbrandt, S., \& Moon, H. (2011). A critical review of the literature on social and leisure activity and wellbeing in later life. Ageing \& Society, 31(04), 683-712.

Aro, R., \& Wilska, T-A. (2014). Standard of living, consumption norms, and perceived necessities. International Journal of Sociology and Social Policy, 34(9), 710-728.

Brajša-Žganec, A., Merkaš, M., \& Šverko, I. (2011). Quality of life and leisure activities: How do leisure activities contribute to subjective well-being? Social Indicators Research, 102(1), 81-91.

Brown, J., MacDonald, R., \& Mitchell, R. (2015). Are people who participate in cultural activities more satisfied with life? Social Indicators Research, 122(1), 135-146.

Bryman, A. (2004). The Disneyization of Society. London: Sage Publications.

Capio, C., Sit, C. P., \& Abernethy, B. (2014). Physical well-being. In A. Michalos (Ed.), Encyclopedia of quality of life and well-being research (pp. 4805-4807). Springer Netherlands.

Carstensen, L. L., Isaacowitz, D. M., \& Charles, S. T. (1999). Taking time seriously. A theory of socioemotional selectivity. The American Psychologist, 54(3), 165-181.

Christoph, B. (2010). The relation between life satisfaction and the material situation: A re-evaluation using alternative measures. Social Indicators Research, 98(3), 475-499.

Dawson, J. (2014). Moderation in management research: What, why, when, and how. Journal of Business and Psychology, 29(1), 1-19.

DeLeire, T., \& Kalil, A. (2010). Does consumption buy happiness? evidence from the United States. International Review of Economics, 57(2), 163-176.

Diener,E., Suh, E.M., Lucas, R.E., Smith, H.L. (1999). Subjective well-being: Three decades of progress. Psychological Bulletin, 125(2), 276-302.

Diener, E. (2006). Guidelines for national indicators of subjective well-being and ill-being. Applied Research in Quality of Life, 1(2), 151-157.

Dodge, R., Daly, A. P., Huyton, J., \& Sanders, L. D. (2012). The challenge of defining wellbeing. International Journal of Well-being, 2(3), 222-235. 
Dolan, P., Peasgood, T., \& White, M. (2008). Do we really know what makes us happy? A review of the economic literature on the factors associated with subjective well-being. Journal of Economic Psychology, 29(1), 94-122.

Dunn, E. W., Gilbert, D. T., \& Wilson, T. D. (2011). If money doesn't make you happy, then you probably aren't spending it right. Journal of Consumer Psychology, 21(2), 115-125.

Easterlin, R. A. (2002). Rich and poor: Disparities, perceptions, concomitants. In W. Glatzer (Ed.), (pp. 157-175). Dordrecht: Springer Netherlands.

Elliot, A. J., Mooney, C. J., Douthit, K. Z., \& Lynch, M. F. (2014). Predictors of older adults' technology use and its relationship to depressive symptoms and well-being. The Journals of Gerontology: Series B: Psychological Sciences and Social Sciences, 69B(5), 667-677.

Eriksson, I., Undén, A., \& Elofsson, S. (2001). Self-rated health. comparisons between three different measures. results from a population study. International Journal of Epidemiology, 30(2), 326333.

Foster, A. C. (2015). Consumer expenditures vary by age. [U.S. Bureau of Labor Statistic] Beyond the Numbers: Prices \& Spending, 4(14)

Galan, I., Meseguer, C. M., Herruzo, R., \& Rodriguez-Artalejo, F. (2010). Self-rated health according to amount, intensity and duration of leisure time physical activity. Preventive Medicine, 51(5), 378-383.

Gouveia, V. V., Vione, K. C., Milfont, T. L., \& Fischer, R. (2015). Patterns of value change during the life span: Some evidence from a functional approach to values. Personality and Social Psychology Bulletin, 41(9), 1276-1290.

Hagger-Johnson, G. (2014). Introduction to research methods and data analysis in the health sciences. New York: Routledge.

Halleröd, B., \& Seldén, D. (2013). The multi-dimensional characteristics of wellbeing: How different aspects of wellbeing interact and do not interact with each other. Social Indicators Research, $113(3), 807-825$.

Halleröd, B., Larsson, D., Gordon, D., \& Ritakallio, V. (2006). Relative deprivation: A comparative analysis of Britain, Finland and Sweden. Journal of European Social Policy, 16(4), 328-345.

Hamilton, K. (2009). Low-income families: Experiences and responses to consumer exclusion. International Journal of Sociology and Social Policy, 29(9), 543-557.

Headey, B., Muffels, R., \& Wooden, M. (2008). Money does not buy happiness: Or does it? A reassessment based on the combined effects of wealth, income and consumption. Social Indicators Research, 87(1), 65-82.

Hietalahti, M., Rantanen, J., \& Kokko, K. (2016). Do life goals mediate the link between personality traits and mental well-being? The Journal of Happiness \& Well-being, 4, 72-89.

Hudders, L., \& Pandelaere, M. (2012). The silver lining of materialism: The impact of luxury consumption on subjective well-being. Journal of Happiness Studies, 13(3), 411-437.

IBM Corp. (2013). IBM SPSS statistics for windows, version 22.0. Armonk, NY: IBM Corp.

Idler, E. L., \& Benyamini, Y. (1997). Self-rated health and mortality: A review of twenty-seven community studies. Journal of Health and Social Behavior, 38(1), 21-37.

Joo, S. (2008). Personal financial wellness. In J.J. Xiao (Ed.), Handbook of consumer finance research (pp. 21-34). New York: Springer.

Katz-Gerro, T. (2004). Cultural consumption research: Review of methodology, theory, and consequence. International Review of Sociology, 14(1), 11-29.

Keyes, C. L. M. (1998). Social well-being. Social Psychology Quarterly, 61, 121-140.

Koivula, A., Räsänen, P., \& Sarpila, O. (2015). Working papers in economic sociology: Suomi 2014 kulutus ja elämäntapa: Tutkimusseloste ja aineistojen 1999-2014 vertailua. Turku: University of Turku.

Kokko, K., Tolvanen, A., \& Pulkkinen, L. (2013). Associations between personality traits and psychological well-being across time in middle adulthood. Journal of Research in Personality, 47(6), 748-756.

Kuykendall, L., Tay, L., \& Ng, V. (2015). Leisure engagement and subjective well-being: A metaanalysis. Psychological Bulletin, 141(2), 364-403.

Le Roux, B., Rouanet, H., Savage, M., \& Warde, A. (2008). Class and cultural division in the UK. Sociology, 42(6), 1049-1071. 
Leadbetter, C., \& O’Connor, N. (2013). Healthy attendance? The impact of cultural engagement and sports participation on health and satisfaction with life in Scotland. Scottish Government Social Research. doi: ISBN 978-1-78256-790-5

Lee, J. H., Lee, J. H., \& Park, S. H. (2014). Leisure activity participation as predictor of quality of life in Korean urban-dwelling elderly. Occupational Therapy International, 21(3), 124-132.

Miles, S. (1998). Consumerism - As a Way of Life. London: Sage Publications.

Moschis, G. P. (2012). Consumer behavior in later life: Current knowledge, issues, and new directions for research. Psychology and Marketing, 29(2), 57-75.

OECD. (2009). Special focus: Measuring leisure in OECD countries. Society at a Glance 2009: OECD Social Indicators (pp. 19-49).

Official Statistics of Finland. (2012). Households' consumption [e-publication]. Helsinki: Statistics Finland.

Official Statistics of Finland. (2011). Time use survey [e-publication]. Changes 1979 - 2009. Helsinki: Statistics Finland.

Penedo, F. J., \& Dahn, J. R. (2005). Exercise and well-being: A review of mental and physical health benefits associated with physical activity. Current Opinion in Psychiatry, 18(2), 189-193.

Ritzer, G. (2010). Enchanting a Disenchanted World: Continuity and Change in the Cathedrals of Consumption. (3rd ed.). New York: SAGE Publications.

Robards, J., Evandrou, M., Falkingham, J., \& Vlachantoni, A. (2012). Marital status, health and mortality. Maturitas, 73(4), 295-299.

Ryan, R. M., \& Deci, E. L. (2001). On happiness and human potentials: A review of research on hedonic and eudaimonic well-being. Annual Review of Psychology, 52, 141-166.

Sassatelli, R. (2007). Consumer culture: History, theory and politics. London: Sage Publications.

Schwartz, S. H. (2012). An overview of the Schwartz theory of basic values. Online Readings in Psychology and Culture, 2(1)

Schwartz, S. H. (2006). Basic human values: Theory, measurement, and applications. Revue Française De Sociologie, 47(4), 249-288.

Segal, B., \& Podoshen, J. S. (2013). An examination of materialism, conspicuous consumption and gender differences. International Journal of Consumer Studies, 37(2), 189-198.

Sewo Sampaio, P. Y., Ito, E., \& Sampaio, R. A. C. (2013). The association of activity and participation with quality of life between Japanese older adults living in rural and urban areas. Journal of Clinical Gerontology and Geriatrics, 4(2), 51-56.

Sheldon, K. M., \& Elliot, A. J. (1999). Goal striving, need satisfaction, and longitudinal well-being: The self-concordance model. Journal of Personality and Social Psychology, 76(3), 482-497.

Smith Maguire, J. (2008). Fit for consumption: Sociology and the business of fitness. London: Routledge.

Stevens, J. P. (2009). Exploratory and confirmatory factor analysis. 5th ed. Applied multivariate statistics for the social sciences (pp. 325-394). Hillsdale, NJ: Routledge.

Taylor, L. (2002). From ways of life to lifestyle: The 'Ordinari-ization'of British gardening lifestyle television. European Journal of Communication, 17(4), 479-493.

Toepoel, V. (2012). Ageing, leisure, and social connectedness: How could leisure help reduce social isolation of older people? Social Indicators Research, 113(1), 355-372.

Valkeneers, G., \& Vanhoomissen, T. (2012). Generations living their own life: The differences in lifestyle and consumer behaviour between busters and baby boomers. Journal of Customer Behaviour, 11(1), 53-68.

Van Boven, L., \& Gilovich, T. (2003). To do or to have? that is the question. Journal of Personality and Social Psychology, 85(6), 1193-1202.

Veenhoven, R., \& Ehrhardt, J. (1995). The cross-national pattern of happiness: Test of predictions implied in three theories of happiness. Social Indicators Research, 34(1), 33-68.

Wang, F., DesMeules, M., Luo, W., Dai, S., Lagace, C., \& Morrison, H. (2011). Leisure-time physical activity and marital status in relation to depression between men and women: A prospective study. Health Psychology : Official Journal of the Division of Health Psychology, American Psychological Association, 30(2), 204-211.

Wheaton, B. (2010). Introducing the consumption and representation of lifestyle sports. Sport in Society, 13(7-8), 1057-1081. 
Windsor, T. D., \& Anstey, K. J. (2010). Age differences in psychosocial predictors of positive and negative affect: A longitudinal investigation of young, midlife, and older adults. Psychology and Aging, 25(3), 641-652.

Wu, S., Wang, R., Zhao, Y., Ma, X., Wu, M., Yan, X., \& He, J. (2013). The relationship between selfrated health and objective health status: A population-based study. BMC Public Health, 13, 3202458-13-320.

Yoon, C., Cole, C. A., \& Lee, M. P. (2009). Consumer decision making and aging: Current knowledge and future directions. Journal of Consumer Psychology, 19(1), 2-16.

Table 1. Rotated factor loadings, Eigenvalues and Cronbach's Alpha for the leisure consumption factors $(n=1340)$

\begin{tabular}{llll}
\hline Variable & Factor loading & Eigenvalue & Alpha \\
\hline Technology & & 1.32 & .67 \\
Entertainment electronics & .74 & & \\
Telecommunications & .51 & & \\
Movies, videos etc. & .45 & & \\
Transport & .41 & 1.36 & .71 \\
Indulgence & & & \\
Having fun, socializing & .83 & & \\
Alcohol & .56 & 4.73 & .71 \\
Self-pampering & .42 & & \\
Appearance & .68 & & \\
Clothes & .67 & 1.01 & \\
Beauty care & .50 & & \\
Home decorations & & \\
Literature \& culture & .96 & & \\
Culture & .44 & & \\
Literature & Kaiser-Meyer-Olkin Measure of Sampling Adequacy=0.86 & \\
Bartlett's Test of Sphericity: Approx. Chi-Square=5213.000, df $105, \mathrm{p}<.001$ & & \\
\end{tabular}

Table 2. Descriptive statistics of the younger $(n=729)$ and older participants $(n=589)$ :

t-test comparisons

\begin{tabular}{llllll}
\hline & $\begin{array}{l}18-49 \mathrm{y} \\
\text { mean }\end{array}$ & $\mathrm{sd}$ & $\begin{array}{l}50-74 \mathrm{y} \\
\text { mean }\end{array}$ & $\mathrm{sd}$ & $\mathrm{t}$-test \\
\hline Emotional well-being & 3.82 & 0.76 & 3.78 & 0.75 & .361 \\
Economic well-being & 3.53 & 0.71 & 3.46 & 0.68 & .090 \\
Self-rated health & 2.83 & 0.88 & 2.49 & 0.86 & $<.001$ \\
Technology & 2.47 & 0.69 & 2.15 & 0.64 & $<.001$ \\
Indulgence & 2.46 & 0.82 & 2.08 & 0.74 & $<.001$ \\
Literature \& culture & 2.25 & 0.90 & 2.21 & 0.87 & .401 \\
Appearance & 2.14 & 0.76 & 2.01 & 0.71 & .001 \\
Exercise & 2.68 & 1.07 & 2.60 & 1.01 & .147 \\
Travel & 2.69 & 1.18 & 2.61 & 1.17 & .181 \\
Health care & 2.38 & 0.93 & 2.67 & 0.93 & $<.001$ \\
Income/capita & 1616.86 & 796.98 & 1982.54 & 858.48 & $<.001$ \\
Education & 3.76 & 1.66 & 3.23 & 1.73 & $<.001$ \\
\hline
\end{tabular}


Table 3. Correlations between the leisure consumption and well-being variables in the younger $(\mathrm{n}=704)$ and older $(\mathrm{n}=661)$ participants

\begin{tabular}{lllllll}
\hline & EmWB & & EcWB & & SRH & \\
& $18-49 \mathrm{y}$. & $50-74 \mathrm{y}$. & $18-49 \mathrm{y}$. & $50-74 \mathrm{y}$. & $18-49 \mathrm{y}$. & $50-74 \mathrm{y}$. \\
\hline Technology & $.01^{\mathrm{a}}$ & $.10^{*}$ & $.23^{* * *}$ & $.25^{* * *}$ & $-.05^{\mathrm{a}}$ & $.08^{*}$ \\
Indulgence & $.05^{\mathrm{a}}$ & $.15^{* * *}$ & $.24^{* * * \mathrm{a}}$ & $.33^{* * *}$ & $.09^{* \mathrm{a}}$ & $.22^{* * *}$ \\
Literature\&culture & $.09^{* \mathrm{a}}$ & $.20^{* * *}$ & $.21^{* * * a}$ & $.38^{* * *}$ & $.09^{* \mathrm{a}}$ & $.18^{* * *}$ \\
Appearance & $.11^{* *}$ & $.17^{* * *}$ & $.27^{* * *}$ & $.28^{* * *}$ & $.13^{* *}$ & $.18^{* * *}$ \\
Travel & $.14^{* * *}$ & $.22^{* * *}$ & $.35^{* * *}$ & $.41^{* * *}$ & $.12^{* * \mathrm{a}}$ & $.25^{* * *}$ \\
Exercise & $.14^{* * *}$ & $.15^{* * *}$ & $.24^{* * *}$ & $.22^{* * *}$ & $.21^{* * *}$ & $.28^{* * *}$ \\
Health care & -.00 & -.05 & $.08^{*}$ & .00 & $-.17^{* * * \mathrm{a}}$ & $-.28^{* * *}$ \\
\hline
\end{tabular}

${ }^{\mathrm{a}}$ Significant difference between age groups in correlation, $\mathrm{p}<.05$, z-test $* \mathrm{p}<.05, * * \mathrm{p}<.01,{ }^{*} * * \mathrm{p}<.001$ $* \mathrm{p}<.05, * * \mathrm{p}<.01, * * * \mathrm{p}<.001$

Table 4. Regression analyses on the well-being measurements for the younger $(n=558)$ and older adults $(\mathrm{n}=760)$, and their interactions

\begin{tabular}{llllllllll}
\hline & \multicolumn{3}{l}{$\begin{array}{l}\text { Emotional well-being } \\
\text { (LR) }\end{array}$} & \multicolumn{4}{c}{$\begin{array}{l}\text { Economic well-being } \\
\text { (LR) }\end{array}$} & \multicolumn{3}{c}{ Self-rated health } \\
& $18-49$ & $50-74$ & $18-74$ & $18-74$ & $18-49$ & $50-74$ & $18-74$ & $18-49$ & $50-74$ \\
\hline Technology & -.01 & -.07 & -.03 & -.04 & $.10^{*}$ & -.04 & .04 & .89 & .92 \\
Indulgence & -.05 & .03 & -.07 & -.02 & $.11^{*}$ & .07 & $.07 *$ & .96 & 1.16 \\
L\&C & .00 & .05 & .04 & .04 & -.02 & $.11^{*}$ & .01 & 1.04 & .99 \\
Appearance & .02 & $.11^{*}$ & .06 & -.00 & .07 & .06 & .06 & $1.34^{*}$ & 1.33 \\
Exercise & $.10^{*}$ & .06 & $.07^{*}$ & $.07^{*}$ & .08 & .05 & $.06^{*}$ & $1.46^{* *}$ & $1.53^{* *}$ \\
Travel & $.14^{* *}$ & $.12^{*}$ & $.12^{* *}$ & $.12^{* * *}$ & $.14^{* *}$ & $.16^{* *}$ & $.14^{* *}$ & 1.18 & $1.20^{*}$ \\
Health care & $-.11^{*}$ & $-.10^{*}$ & $-.11^{* * *}$ & $-.11^{* * *}$ & -.06 & -.04 & -.05 & $.56^{* * *}$ & $.46^{* *}$ \\
& & & & & & & & & \\
Age & .04 & .03 & .01 & .01 & $.11^{* *}$ & .02 & -.03 & .99 & 1.02 \\
Gender & .03 & $.09 *$ & $.06^{*}$ & $.06^{*}$ & .03 & .02 & .03 & $.74^{\mathrm{b}}$ & $.74^{\mathrm{b}}$ \\
Education & .09 & .03 & .06 & .06 & $.11^{* *}$ & $.12^{* *}$ & $.11^{* *}$ & $1.13^{*}$ & 1.09 \\
Income/capita & .01 & $.14^{* *}$ & $.08^{* *}$ & $.09^{* *}$ & $.26^{* *}$ & $.30^{* *}$ & $.29^{* *}$ & 1.00 & 1.00
\end{tabular}

Interactions

Age $\mathrm{e}^{\mathrm{*} \text { Indulgence }}$

$.09 *$

Age ${ }^{\mathrm{a} *}$ Appearance

$.09 *$

Age $^{\mathrm{a} *} \mathrm{~L} \& \mathrm{C}$

.05

Adj. R²

$\begin{array}{lll}.04 & .10 & .09\end{array}$

$.26 \quad .31$

.28

$.17^{\mathrm{c}}$

$.23^{\mathrm{c}}$

All models $\mathrm{p} \leq .001$

${ }^{*} \mathrm{p}<.05, \quad * * \mathrm{p}<.01, \quad * * *<.001$. LR=Linear regression, standardized $\beta$ coefficient presented. OR=Ordinal regression, odds ratios presented. $\mathrm{L} \& \mathrm{C}=$ Literature $\&$ culture.

${ }^{a} \mathrm{Age}$ is a continuous variable in the models for age groups $18-49$ and $50-74$, and a dichotomous variable in the interaction models. ${ }^{\mathrm{b}}$ Reference group (1.00) women. ' Nagelkerke $\mathrm{R}^{2}$ 
Table 5. Regression analyses on well-being measurements for older adults $(n=760)$

\begin{tabular}{|c|c|c|c|c|c|c|c|c|}
\hline \multirow[b]{2}{*}{ Technology } & \multicolumn{3}{|c|}{ Emotional well-being (LR) } & \multicolumn{2}{|c|}{$\begin{array}{l}\text { Economic well- } \\
\text { being (LR) }\end{array}$} & \multicolumn{3}{|c|}{$\begin{array}{l}\text { Self-rated health } \\
(\mathrm{OR})\end{array}$} \\
\hline & -.06 & -.06 & -.09 & -.07 & -.07 & .97 & .98 & .94 \\
\hline Indulgence & .04 & .11 & .04 & .07 & .01 & 1.27 & 1.14 & 1.13 \\
\hline $\mathrm{L} \& \mathrm{C}$ & $.15^{*}$ & .04 & .04 & .08 & .09 & .98 & .98 & .1 .01 \\
\hline Appearance & $.11 *$ & .10 & $.11^{*}$ & .07 & .07 & 1.23 & 1.24 & $1.25^{*}$ \\
\hline Exercise & .07 & .06 & .06 & -.05 & .05 & $1.58 * * *$ & $1.59 * * *$ & $2.13 * * *$ \\
\hline Travel & $.11^{*}$ & $.11^{*}$ & $.11^{*}$ & $.16^{* * *}$ & $.17 * * *$ & $1.22 *$ & $1.45^{* *}$ & $1.22 *$ \\
\hline Health care & $-.10^{*}$ & $-.10^{*}$ & .01 & -.03 & -.03 & $.48 * * *$ & $.48 * * *$ & $.48 * * *$ \\
\hline Gender & $.09 *$ & $.09^{*}$ & $.09^{*}$ & .02 & .02 & $.72^{\mathrm{b}}$ & $.72 * b$ & $.71^{* \mathrm{~b}}$ \\
\hline Education & .04 & .04 & .02 & $.11 * *$ & $.11 * *$ & 1.10 & 1.10 & 1.08 \\
\hline Income/capita & $.14 * *$ & $.14^{*}$ & $.12 * *$ & $.27 * * *$ & $.26 * * *$ & 1.00 & 1.00 & 1.00 \\
\hline $\mathrm{Age}^{\mathrm{a}}$ & .07 & .05 & $.16^{*}$ & $.20 * * *$ & $.20 * * *$ & $.72^{\mathrm{b}}$ & $.69 * b$ & 1.02 \\
\hline ES & & & $-.16^{*}$ & $-.25 * * *$ & $-.24 * * *$ & & & \\
\hline MS & & & & & & & & $.81^{\mathrm{b}}$ \\
\hline \multicolumn{9}{|l|}{ Interactions } \\
\hline $\mathrm{Age}^{\mathrm{a} * \mathrm{~L} \& \mathrm{C}}$ & $-.16^{* *}$ & & & & & & & \\
\hline Age $^{a * \text { Indulgence }}$ & & -.09 & & & & .82 & & \\
\hline Age $^{\mathrm{a} * \text { Travel }}$ & & & & & & & $.70^{*}$ & \\
\hline ES*Health care & & & -.13 & & & & & \\
\hline ES*Exercise & & & & $.14^{*}$ & & & & \\
\hline ES*Indulgence & & & & & .08 & & & \\
\hline MS* Exercise & & & & & & & & $.64 * *$ \\
\hline Adj. $R^{2}$ & .11 & .11 & .11 & .34 & .34 & $.24^{\mathrm{c}}$ & $.24^{\mathrm{c}}$ & $.24^{\mathrm{c}}$ \\
\hline
\end{tabular}




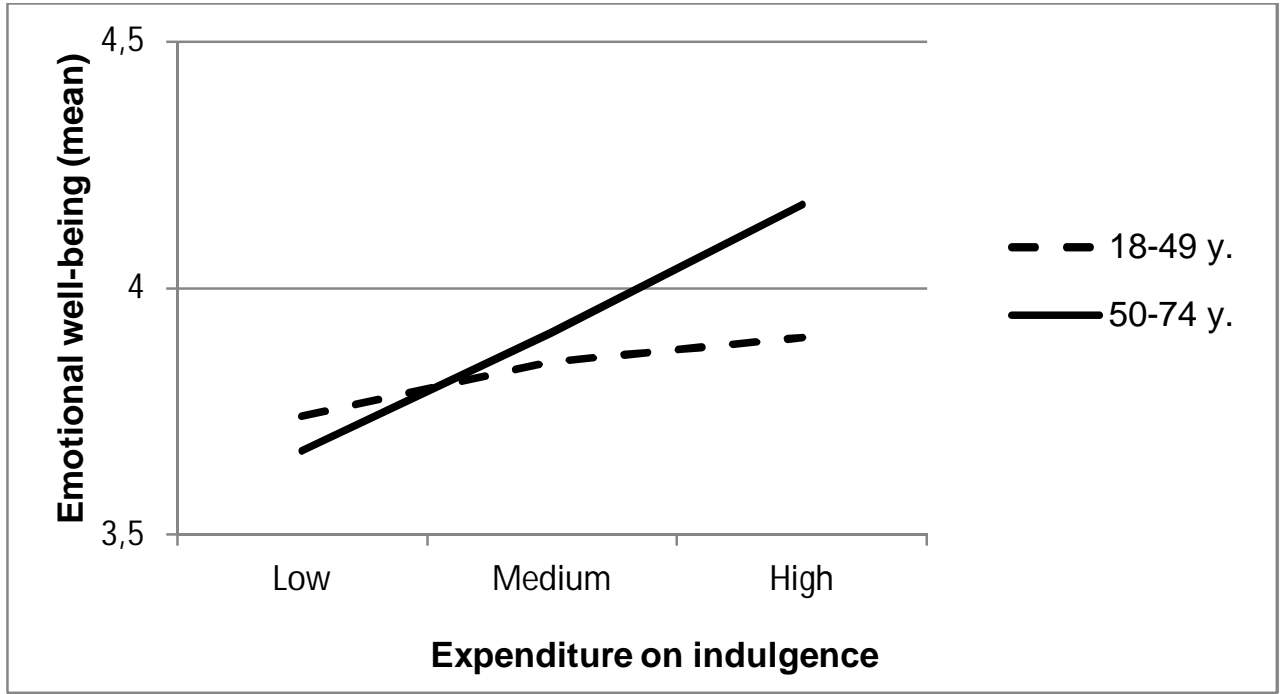

Fig. 1 Interaction effect between expenditure on indulgence and age on emotional well-being $(n=$ 1307)

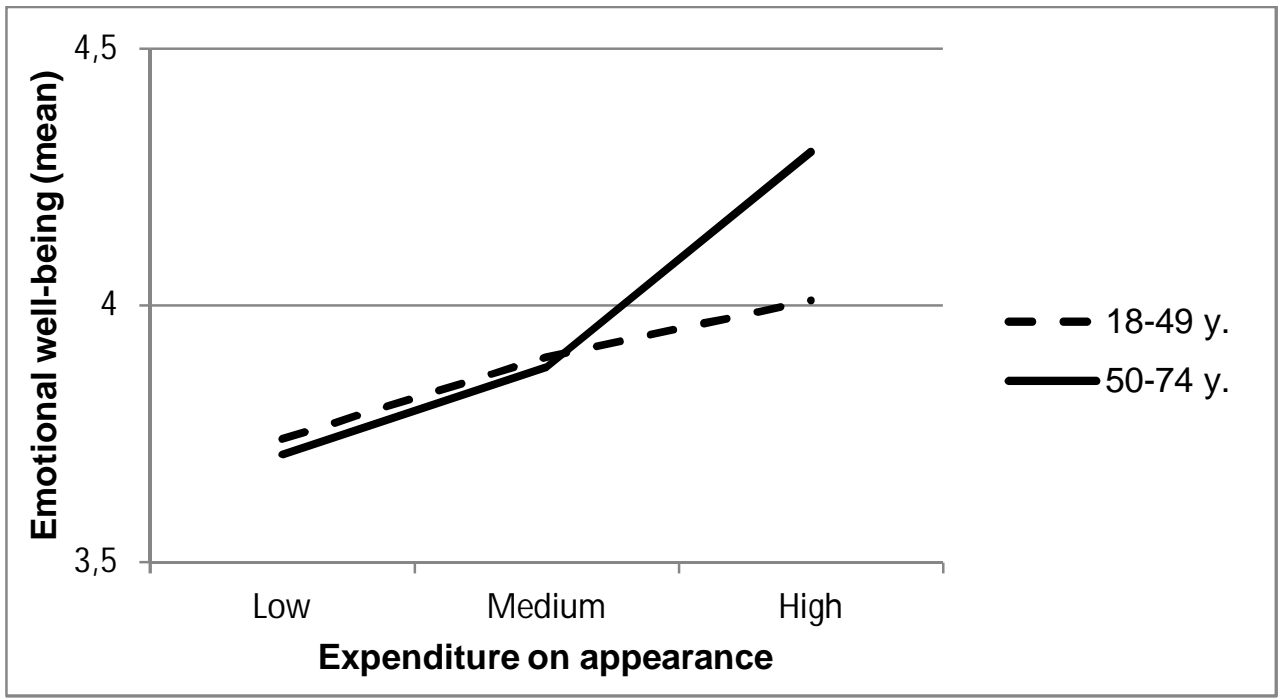

Fig. 2 Interaction effect between expenditure on appearance and age on emotional well-being $(\mathrm{n}=$ 1307) 


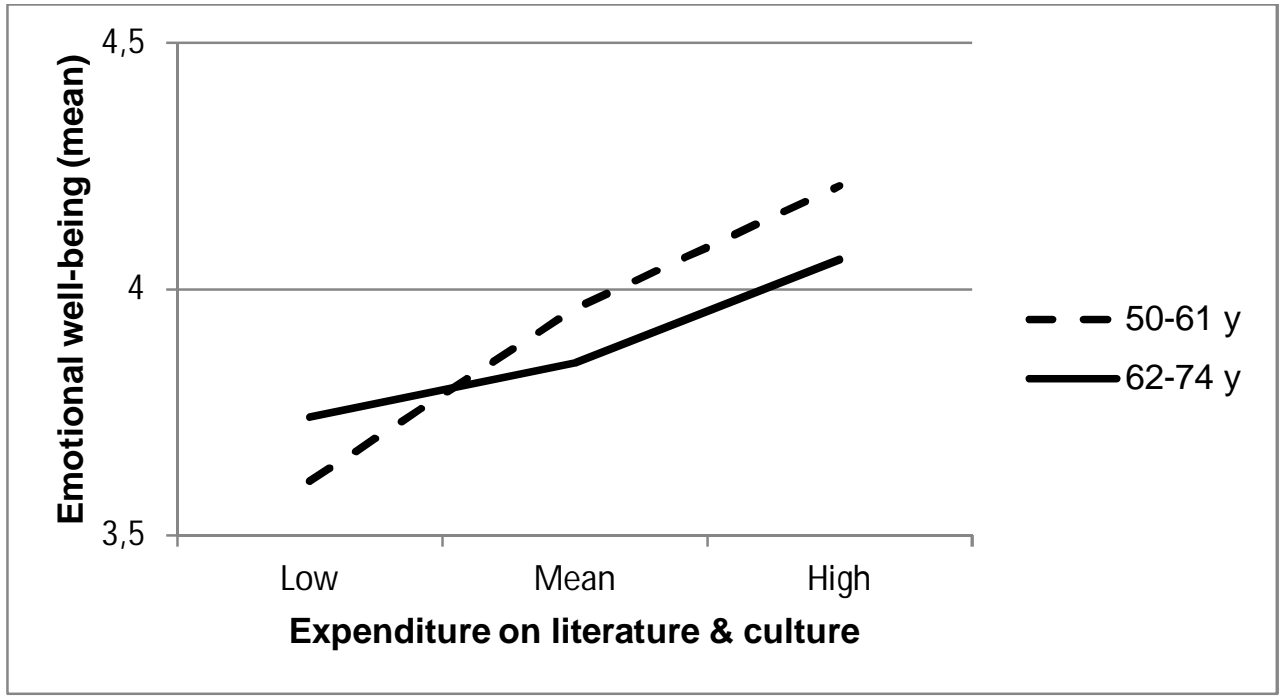

Fig. 3 Interaction effect between expenditure on literature \& culture and age on emotional well-being $(\mathrm{n}=575)$

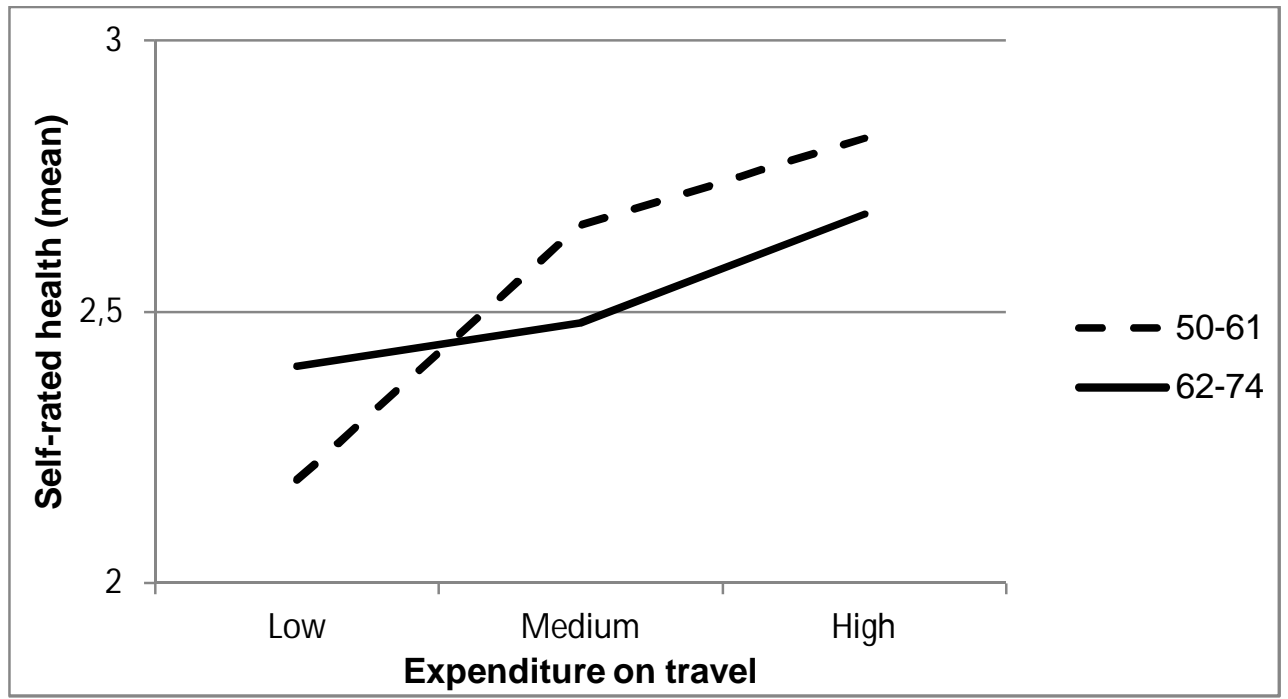

Fig. 4 Interaction effect between expenditure on travel and age on self-rated health $(n=571)$ 


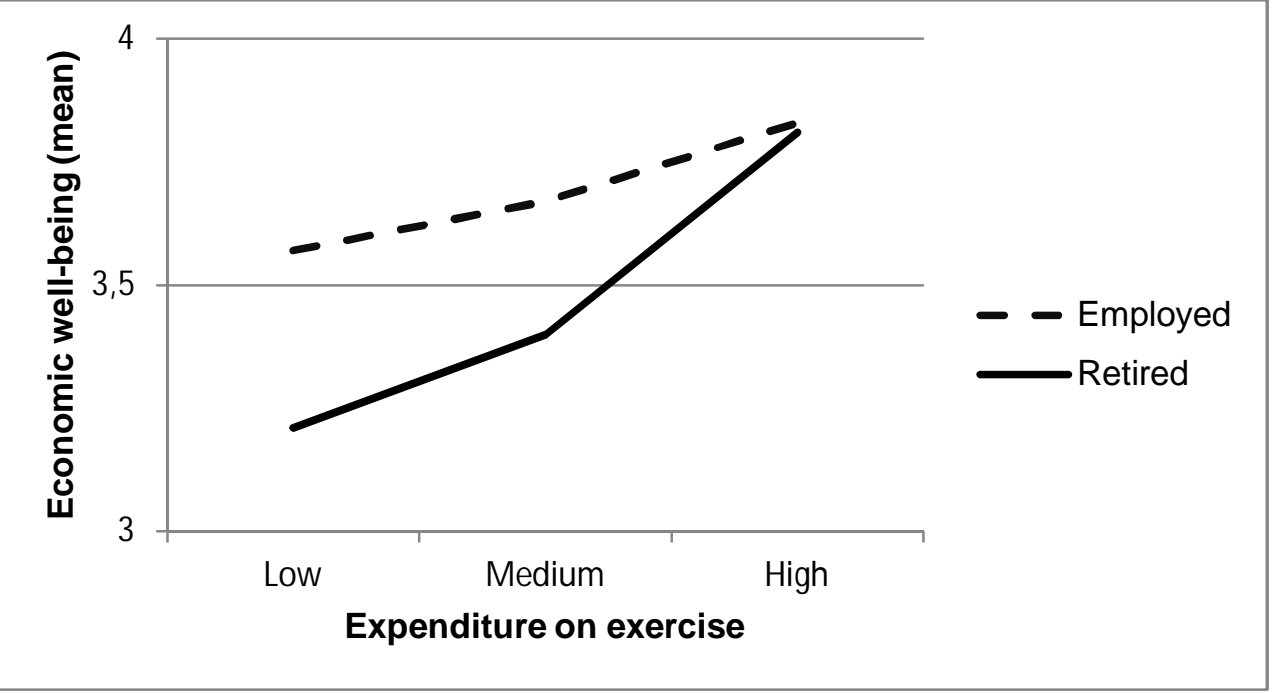

Fig. 5 Interaction effect between expenditure on exercise and employment status on economic wellbeing $(n=531)$

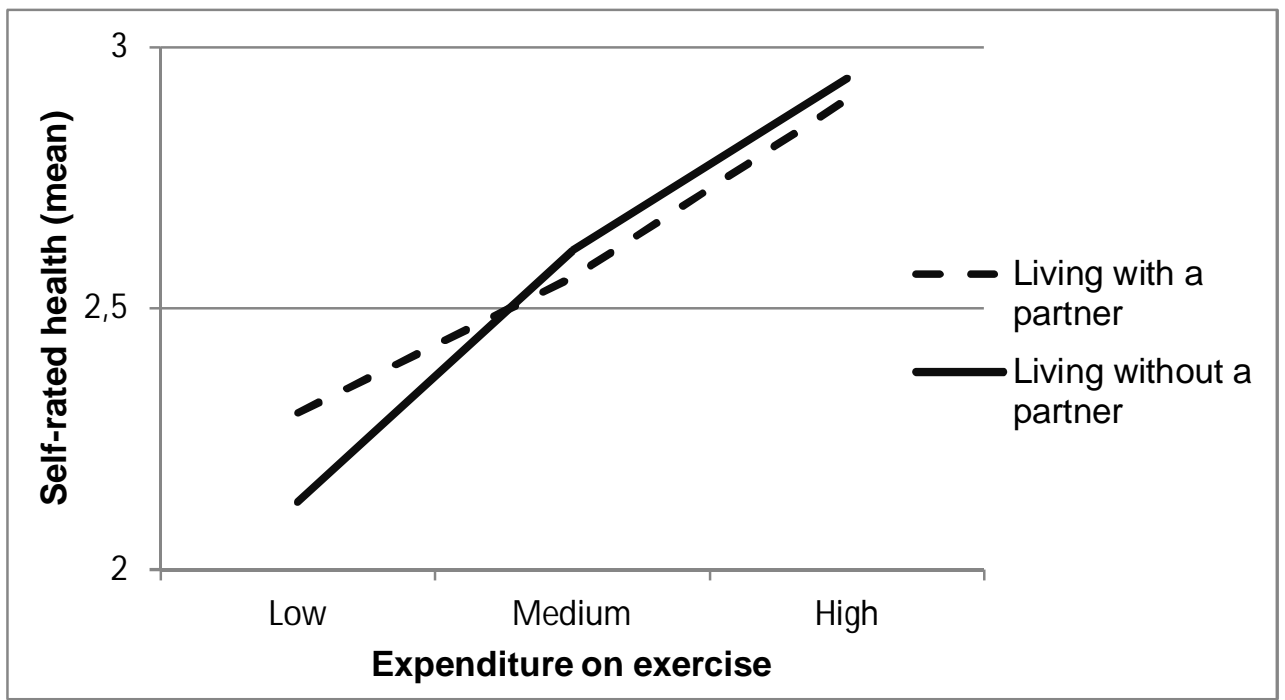

Fig. 6 Interaction effect between expenditure on exercise and marital status on self-rated health $(\mathrm{n}=$ 571) 